\title{
Resenhas
}

\section{Reflexões sobre blue jeans e motocicletas, pessoas cinzas normais...}

Reflections on blue jeans and motorcycles, normal gray people... Reflexiones sobre blue jeans y motocicletas, gente gris normal...

Helton Saragor de Souza(a)

<hs.souza@unifesp.br> iD
(a) Departamento de Políticas Públicas e Saúde Coletiva, Universidade Federal de São Paulo. Rua Silva Jardim, 136, Vila Mathias. Santos, SP, Brasil. 1015-020.

O cinema contribuiu significativamente para o debate público sobre o trabalho na sociedade contemporânea. O cotidiano dos trabalhadores e populações ao redor do globo no século 20 e nas primeiras décadas do século 21 foi retratado por meio da expressão audiovisual ${ }^{1}$. As narrativas dos documentários ofertam acesso às relaçôes de trabalho e à vida dos indivíduos, a dramas e realizaçôes pessoais atravessadas pelo denominador comum da exploração e da necessidade de sobrevivência na sociabilidade capitalista. $\mathrm{O}$ "desenrolar" dos enredos dessas produçôes apresentam semelhanças de como a produção capitalista estabelece formas dominantes internacionalmente e na sujeição da humanidade.

Essa característica possibilitou mediações pedagógicas relevantes na análise crítica das obras², e ao analisar documentários encontramos "pontos de encontros" de relaçôes análogas em locais particulares. Essa reflexão é um caminho promissor para a abordagem em graduações de saúde, educação, serviço social e humanidades, ou seja, por meio da tela se pode compreender a produção social da saúde e da doença e as configuraçốes diversas de agravos à saúde do trabalhador. 
O documentário de Marcelo Gomes, "Estou me guardando para quando o Carnaval chegar”, apresenta a capital nacional do jeans, Toritama (PE), por meio da memória afetiva do diretor. A cidade pacata de outrora que visitara na infância na companhia de seu pai contrasta com a atual cidade homogeneizada pela produção têxtil. Na entrada da cidade, "totens publicitários" propagam modelos brancos de jeans assemelhados dos personagens do main stream cultural norte-americano, por trás da série de outdoors se revelam as entranhas da produção fabril no agreste pernambucano, mas a planta fabril não é mais um galpão organizado como oficina manufatureira, é a própria cidade. Suas ruas de terra funcionam como corredores da planta industrial, motos e carroças transportam as peças compondo os barulhos persistentes oriundos das máquinas de costura e demais equipamentos das "facções", pequenas unidades produtivas instaladas nas residências em seus quintais e garagens.

A cidade-fábrica não se constitui pelo desenvolvimento de trabalhos complexos combinados, mas pela dedicação integral e a redução a um gênero, como diz um entrevistado: “... se o jeans se acabar, 99\% de Toritama se acaba”. Os trabalhadores-moradores expressam orgulho e dizem "Toritama é trabalho", terra de oportunidades; logo, não é mais necessário o fluxo migratório para São Paulo para trabalhar, pois se quiser não faltará trabalho. Assim como a marca da fome e da sobrevivência também se expressam, “...a pessoa chega [em Toritama] com a barriga lá dentro e sai obesa...”, mas advertem: caso queira se divertir é necessário sair da cidade.

A condensação do passado e do presente dos paradigmas da produção industrial capitalista tem em Toritama sua máxima expressão. Do mesmo modo, a realidade do trabalho contemporâneo e da formação social brasileira estão imbricadas. Na condução das tarefas padronizadas aos moldes tayloristas, "o balé das mãos” dos movimentos repetitivos e adestrados no corte, na costura, na lavagem, no tingimento, no acabamento e na limpeza conforma a habilidade de produzir acompanhada do suor e da intensidade, enquanto calças e retalhos do jeans se amontoam. Assim como o pagamento por peça produzida ou, nos próprios termos dos trabalhadores, "você ganha pelo que você faz" ou "quanto mais você arrochar, mais você ganha”. A ausência de salário ou pagamento de valores-base mínimos se associam à extensão da jornada de trabalho.

A sinfonia caótica marca a simbiose das máquinas e de mulheres e homens, o barulho ensurdecedor causa ansiedade no narrador, ao passo que a repetição lhe causa angústia, embora tente outra estética de ângulo para retratar a cena, e suspender o som industrial torna-se imperioso e insere a música clássica de $\mathrm{Bach}^{3}$ na trilha sonora. Som e imagem incompatibilizam-se em polos, ouvimos a expressão da realização humana fundamentada na criação e no pensamento, enquanto vemos a ação repetitiva da produção, do automatismo do trabalho e da vida. O diretor reflete que Toritama tinha outra velocidade e observa que silêncio durava o dia inteiro, mas agora o silêncio só se conhece na hora do almoço.

As formas mais primárias de organização do trabalho do século 19 do centro capitalista ressurgem como tendência avassaladora sobre diversos segmentos de trabalhadores pelo mundo, e pretendem inviabilizar qualquer relação salarial, estabilidade ou direitos trabalhistas característicos do período fordista e transpostados com restriçóes para a realidade periférica entre as décadas de 1950 e 1970. Todavia, a produção-exploração 
não se resume à forma taylorista no controle de tempos e movimentos. A produção local é totalmente conectada aos paradigmas contemporâneos da acumulação flexível; a reestruturação produtiva ${ }^{4}$ aparece na vida, conforme o caso da "dona” de facção que, antes trabalhadora de uma confecção, com o dinheiro oriundo da demissão comprou maquinário e tornou-se "proprietária”.

A realidade de Toritama é desenhada pelos ditames da fast fashion ${ }^{5}$ que combina, por um lado, com o estabelecimento de um padrão de consumo de vestimentas como mercadorias baratas em grandes centros e, por outro, com a mundialização das relaçóes do capital e da exploração da força de trabalho para os diversos rincóes por meio da externalização de unidades produtivas, seja na forma das “fábricas de suor”, unidades com infraestrutura precária presentes no sudoeste asiático, também visíveis em Toritama, seja como organização produtiva em casas, nos moldes de pequenas facçóes padrão industrial ou "pré-industrial” encomendadas por grandes players da indústria da moda.

O documentário pernambucano agrega à filmografia mundial duas produçôes emblemáticas sobre a indústria têxtil: o documentário gravado clandestinamente, China Blue ${ }^{6}$ que narra a história de duas adolescentes imigrantes que moram na fábrica da produção chinesa de calças jeans e desejam enviar uma carta no bolso de uma das calças para que o consumidor saiba o que acontece em seu cotidiano; e The True Cost ${ }^{7}$, que expõe as tragédias sociais e ambientais da externalização da produção na Ásia em contraste com o marketing das grandes marcas.

As três produçốes documentais visibilizam os métodos ultrajantes consagrados na revolução industrial no século 21: a intensa exploração de populaçốes pobres que lutam pela sobrevivência; o tempo incessante de trabalho garantido pela interseção do local de moradia e de produção; o pagamento por peça produzida sempre irrisório em referência ao preço comercializado; o corpo cedendo ao cansaço ao passo que ficar fora de combate por adoecimento não é uma escolha pela ausência de direitos trabalhistas. Em síntese, o cotidiano homogeneizado pela produção e as belas mercadorias de um trabalho sob condiçốes aviltantes.

Contudo, o documentário nacional sobre a cidade do agreste pernambucano oferta o olhar de como as formas contemporâneas do trabalho se associam à formação social brasileira, princípios extremados da acumulação flexível. A polivalência "desejada” dos trabalhadores no toyotismo se associa ao "fazer de tudo" para sobreviver, não vinculado à qualificação operária, mas às atividades de baixa qualificação presentes no histórico profissional dos trabalhadores que transitaram entre o rural e o urbano, na lavoura de cana, arrancando tocos, cavando buracos e na construção civil. Sendo assim, o trabalho na confecção do jeans não é difícil. Da mesma maneira que não é mais necessário chefe de seção, gerente ou fiscal de tempos e movimentos com o cronômetro taylorista, os trabalhadores internalizam a relação das atividades produtivas e do tempo.

A mudança do tempo em Toritama demonstra como a disciplina do trabalho sob o capitalismo industrial constitui um tempo ${ }^{8}$ de sociabilidade próprio por meio da produção. Toritama é a cidade na qual o tempo coletivo preenchido é por um trabalho sem fim, assinala o documentarista. A conformação do tempo é condicionada pela diversificação e pelo barateamento das mercadorias para realizar e acelerar o consumo nos parâmetros da fast fashion. 
O acabamento manual ou nas máquinas de laser que marcam em detalhes as roupas é uma etapa importante da produção, porque segundo o vendedor-estilista-modelo Zé do Ouro: a roupa precisa ter detalhes para vender, porque senão não vende. Essa mutação na velocidade e no tempo da cidade resulta no volume assustador de peças de jeans, entre $15 \%$ e $20 \%$ da produção nacional, na abundância das mercadorias expostas nas lojas e também na abundância de tempo de trabalho despendido em um ritmo cada vez mais acelerado do movimento do capital.

A disciplina capitalista sobre os indivíduos se materializa na dinâmica contemporânea pelo pressuposto de que o tempo de trabalho "engoliu” o tempo de não trabalho, assim como o ciclo de vida e suas identidades são costurados pelo ritmo das máquinas; as crianças brincam e correm entre elas; os jovens comentam sua vida afetiva e paternidade sobre seu barulho; e, na calçada das casas, os idosos substituem a cadeira de balanço no passar dos tempos para aproveitá-lo fazendo a limpeza do jeans, última fase da produção.

Os diversos momentos marcam a disciplina do trabalho e do preenchimento das relaçóes e, sobretudo, da mudança de cultura pela indústria capitalista que transforma a cidade, a vida e os sonhos de seus moradores. Contudo, os trabalhadores autônomos são orgulhosos de serem "donos de seu próprio tempo", a dona da facção entra e sai na hora que quiser, todavia trabalha no período das sete horas até $22 \mathrm{~h} 30 \mathrm{da}$ noite.

Ademais, inclusive, o descanso das refeiçôes é funcional para o exercício do trabalho e sua maior intensificação; a extensão da jornada "permite" intervalos como se fossem privilégios. Essa disposição do tempo se efetiva ao adentrar o espaço doméstico com os termos dos moradores: trabalhar em casa não cansa, convencidos de que quanto mais trabalharem, mais ganharão.

Essa relação de trabalho, embora tenha elementos históricos gerais, se efetiva na realidade brasileira; o processo de proletarização na formação social do país ganha novos contornos combinados com os novos paradigmas de produção. Anteriormente, o ingresso no mercado de trabalho por meio do assalariamento no período de urbanização era visto como privilégio ao indivíduo e sua família porque eles se destacavam do contingente populacional que lutava pela subsistência na persistente informalidade.

Contudo, agora a relação salarial não está acessível para regiões e segmentos inteiros, os "privilegiados" se tornam aqueles que recebem algo pelo seu trabalho, logo passam a ser integrados, em Toritama, a cerca de $95 \%$ dos trabalhadores informais 9 . Afinal de contas, como relatam: trabalhar é um privilégio, basta ver os outros países com guerras ou mesmo a fome na África. Essas relações de trabalho, nas quais a pressão para a redução do preço da força de trabalho é central no movimento do capital, são espelho das condiçóes de vida de uma sociedade em que direitos trabalhistas e previdenciários se esvaem combinados com o recrudescimento da fome.

A sobrevivência dos trabalhadores na questão da moradia se efetiva de modo particular no Brasil. O processo de autoconstrução habitacional ${ }^{10}$ vinculado à acumulação do capital, na medida em que o próprio trabalhador constrói sua moradia, ocorre com a redução do preço da força de trabalho, pois o custo de aquisição de habitação é retirado do salário. $\mathrm{Na}$ realidade de Toritama, essa relação é ampliada; a expansão de novos bairros e as novas residências também são a expansão das facções. 
O trabalhador Léo, destacado no documentário, constrói a casa com a promessa de trabalho na nova facção; a autoconstrução transforma-se em incremento de produção; logo, transfere-se o custo básico do capital incorporado pela força de trabalho e sua atividade laboral para a exploração sobre todos os âmbitos de vivência.

A diminuição dos custos de infraestrutura é mundialmente imperiosa nesse ramo de atividade, conforme exemplificação das tragédias recorrentes e do desastre do prédio destinado a confecção que desmoronou com trabalhadores dentro em Bangladesh, ou mesmo em grandes cidades brasileiras como São Paulo, na qual imigrantes, principalmente bolivianos, costuram em locais insalubres.

Como as pessoas de Toritama vivem e entendem sua vida é uma contribuição primordial ofertada pelo documentário: os indivíduos avaliam que escolheram trabalhar desse modo e não vivenciam a relação de trabalho como uma movimentação do capital em "priorizar" a região. A formação histórica da consciência dos trabalhadores na sociedade desigual brasileira e sua visão de inserção no mercado de trabalho se combina aos atuais ditames da flexibilização. O trabalhador Léo diz: "tudo na vida é o trabalho" e mesmo no corte de cana "ninguém manda em você, porque também se trabalha por produção". No conjunto dos relatos, entende-se que trabalhar "autonomamente” se trata da melhor profissão do mundo, não trabalhar para ninguém, não ser empregado, e esse entendimento se associa à projeção de riqueza: aquele que tem acesso ao jeans, "ouro azul” de Toritama, ficará rico.

Essa simbologia aparece na música tocada na facção "Sonhei que tava rico" 11 . Os trabalhadores vivem e se mobilizam pela identidade de donos do próprio negócio e projetam ser futuros patróes. A simbiose da tradição das feiras de domingo de cidades interioranas com o trabalho adicional de comercialização força os trabalhadores a dormirem de um dia para o outro na feira.

O narrador imagina os sonhos alheios: ver a empresa crescer, ter uma casa, tirar o quanto máximo, ser dono da própria facção. A ideia de serem patrôes de si mesmos é incorporada na identidade e erode o sujeito pelo tempo de trabalho e, consequentemente, sua sociabilidade, pois vive mobilizado por essa ideia.

Indubitavelmente, existe uma "mina de ouro" em Toritama, montante de valor muito precioso, e o acesso a esse contingente de trabalhadores gera riqueza; todavia os trabalhadores estão na relação social de inversão do sujeito e do objeto, a valorização do mundo das coisas é proporcional à desvalorização dos homens. Os trabalhadores perseguem a riqueza, quando seu próprio cotidiano é fonte de riqueza para outrem. O desgaste é uma resultante óbvia, a cena do trabalhador cansado dormindo em cima das calças de jeans expóe o corpo desmanchando ao cansaço e na condição de objeto disposto em cima das mercadorias que produz; cena idêntica é captada no documentário sobre a produção chinesa de calças jeans.

Embora a dinâmica da produção seja totalizante e condicione a consciência, advogar que os trabalhadores de Toritama entendem de forma "inadequada" o sentido de sua vida é equivocado; ou desconsiderar a existência de outros espaços de sociabilidade, como igrejas, bares, espaços familiares, que não aparecem no documentário. 
Sobretudo, observamos vivências e ambiguidades que negam a toada; o pastor do rebanho assinala: para quê ganhar "muito" dinheiro? E humilhar os outros! Relata que, para um conhecido seu, Deus é o dinheiro, assim como uma agricultora diz "Deus me livre" a respeito de trabalhar na confecção, enquanto os vizinhos trocaram a criação de galinhas por máquinas de costura. Do mesmo modo, Léo, o trabalhador polivalente à brasileira, diz “...o dinheiro é a maldição do mundo, quem nasceu para ter, tem, e quem não nasceu para ficar sem nada, ficará sem nada”.

A simbologia do Carnaval como o momento de suspensão da vida cotidiana diz muito do modo como os indivíduos vivenciam o trabalho, que aparentemente é fugir das obrigações para o encontro do prazer nos moldes de sua atribuição na sociedade nacional, mas para os moradores-trabalhadores de Toritama significa sobretudo desafogo: a suspensão do trabalho. Não à toa, eles relatam tristeza e arrependimento em ficar na cidade deserta no Carnaval.

As pessoas agarram desesperadamente o único evento e o período do ano não ligados ao trabalho que conferem algum sentido na sua vida; vendem itens como geladeiras para poder ir à praia e as compram depois, mesmo por um preço maior. $\mathrm{O}$ objetivo é "sair dessa correria, dessa coisa de doido, dessa loucura" diz o comerciante dos itens usados que relata já ter desmaiado de stress. Contudo, os dias posteriores explicitam que não cabem idealizaçôes do Carnaval, pois o curto período de não trabalho também apresenta funcionalidade pelo seu caráter de suspensão da produção para o seu retorno em ritmo intensificado.

A mobilização ideológica parte da história das relaçóes de trabalho no Brasil e constitui identidades de trabalhadores no parâmetro do capitalismo contemporâneo: a combinação do arcaico e do ideário de "valores futuros", a projeção da ostentação e do consumo de mercadorias. Não obstante pareça contraditório, depreendemos a interpretação do país e do trabalho contemporâneo pela realidade interiorana de Toritama, nome que significa "terra da felicidade” e representa um país com as remanências do passado escravocrata de que os indivíduos são felizes ao trabalharem. A cidade também projeta ser um laboratório das relaçôes de trabalho contemporâneas com a erosão de direitos e a mobilização ideológica, a ponto de um trabalhador encarar "a carteira assinada" como algo prejudicial, pois advoga ter mais ganhos desse modo.

Certamente, os trabalhadores-moradores de Toritama terão em suas histórias de vida, nas suas relaçóes pessoais e no corpo a manifestação do trabalho e da vida materializados; os relatos daqui uns anos expressarão a reflexão da vida vivida para o trabalho no ritmo cadenciado pela máquina de costura e pela demanda do consumo de vestuário. 


\section{Conflito de interesse}

$\mathrm{O}$ autor não tem conflito de interesse a declarar.

\section{Direitos autorais}

Este artigo está licenciado sob a Licença Internacional Creative Commons 4.0, tipo BY (https://creativecommons.org/licenses/by/4.0/deed.pt_BR).

\section{(cc) BY}

\section{Editor}

Antonio Pithon Cyrino

Editora associada

Mariana Arantes Nasser

\section{Submetido em}

03/05/21

Aprovado em

$21 / 07 / 21$

\section{Referências}

1. Ruy CB. O mundo do trabalho no cinema. São Paulo: Centro de Memória Sindical; 2015.

2. Alves G. Tela crítica: a metodologia. São Paulo: Editora Práxis; 2010.

3. Bach JS. Concerto para piano e orquestra no 5 em fá menor. Gravação de João Carlos Martins. São Paulo: Atração Fonográfica; 2006.

4. Krost O. O lado avesso da reestruturação produtiva: a "terceirização" de serviços por "facçôes”. Blumenau: Nova Letra; 2016.

5. Taplin IM. "Who is to blame? A re-examination of fast fashion after the 2013 factory disaster in Bangladesh”. Crit Perspect Int Bus. 2014; 10(1):72-83.

6. Peled MX. Direção e Roteiro. China Blue. Independent Lens. PBS. Estados Unidos, 2005. [Documentário] (86 min).

7. Morgan A. Direção e Roteiro. The True Cost: Who Pays the Real Price for YOUR Clothes | Estados Unidos, 2015. [Documentário] (92 min).

8. Thompson EP. Costumes em comum: estudo sobre cultura popular tradicional. São Paulo: Companhia das Letras; 1988.

9. Santos BB, Vasconcelos VM. Fatores socioeconômicos e demográficos associados ao trabalho informal: o caso de Toritama, Pernambuco, Brasil. Contemporânea. 2018; 8(1):289-316.

10. Oliveira F. O vício da virtude: autoconstrução e acumulação capitalista no Brasil. Novos Estud. 2006; (74):67-85.

11. BETONI. Sonhei Que Tava Rico (single) [Internet]. Youtube; 2019 [citado 3 Mar 2021]. Disponível em: https://www.youtube.com/watch?v=VGMIiKoaOZU 